\title{
THE FRUITING ECOLOGY OF OSYRIS QUADRIPARTITA: INDIVIDUAL VARIATION AND EVOLUTIONARY POTENTIAL ${ }^{1}$
}

\author{
CARlos M. HerRera \\ Estación Biológica de Doñana, E-41013 Sevilla, Spain
}

\begin{abstract}
The fruiting ecology of Osyris quadripartita (Santalaceae), a hemiparasitic evergreen shrub, was studied over a 4-yr period in a Mediterranean scrubland of southern Spain. In addition to describing the natural history of seed dispersal in this species, objectives of the study were (1) to document patterns of individual and annual variation in seed-dispersal-related traits (fruit characteristics, crop size, fruiting phenology); (2) to determine the consequences, in terms of dispersal success, of individual variability; and (3) to examine the significance, in terms of differential reproductive output, of individual variability in dispersal-related attributes, in an attempt to evaluate the evolutionary potential for modification of these traits. In this species during the 4-yr period considered, dispersal-related traits, although relevant to dispersal rates, were unrelated to individual differences in fitness because dispersal rates were irrelevant to fitness.

$O$. quadripartita plants produce ripe fruits almost continuously, and most individuals have fruiting periods virtually encompassing the entire year. Significant individual variation exists in average fruiting schedule, crop size, and fruit characteristics. The peak of the fruiting period of individual plants may occur in almost any month of the year. Phenology, crop size, and fruit characteristics differ in the degree to which differences between individuals remain consistent from year to year in the face of population variation in these variables. Individual differences in crop size remain invariant among years, while differences in phenology and fruit characteristics do not. Individual variation in crop size is related to flower number, while annual differences are explained by variation in summer rainfall through influences on latent ovary abortion rates. There is within-plant seasonal variation in fruit characteristics, and there are also significant interplant and interannual differences in the way fruit characteristics change seasonally. Avian frugivores are present in the habitat throughout the year, but seasonal changes in abundance and amount of frugivory delimit distinct periods of high and low demand for $O$. quadripartita fruits. The probability of damage to ripe fruits depends on time of year (although there is considerable annual variation), crop size, and fruit size. Large fruits in small crops predictably face the highest probabilities of damage, and small fruits in large crops the lowest. The relation between the probability of damage and crop size, however, varied among plants and seasonally.

Individual differences in fruit characteristics and crop size, but not in phenology, are related to individual variation in seed dispersal rates (proportion of ripe fruits dispersed). Nevertheless, dispersal rate accounts for only $0.2 \%$ of individual variation in relative contribution to the population's realized reproductive output, while estimated total number of fruits ripened accounts for $96 \%$. This pattern is consistent from year to year. Components of interindividual variation that influence the dispersal prospects of fruits are eventually unimportant in accounting for individual variation in relative reproductive contribution.
\end{abstract}

Key words: avian frugivory; crop size; fruit characteristics; fruiting phenology; individual variability; Mediterranean scrublands; Osyris; root hemiparasites; Santalaceae; seed dispersal.

\section{INTRODUCTION}

In recent studies of the ecology of seed dispersal by vertebrates it is explicit or implicit that there is a potential for evolutionary change in the participants in this mutualistic interaction. This attitude may be traced to the seminal contributions of Snow $(1965,1971)$ and McKey (1975). In this context, a variety of plant and

\footnotetext{
${ }^{1}$ Manuscript received 2 January 1986; revised 4 May 1987; accepted 18 May 1987.
}

vertebrate attributes related to seed dispersal or frugivory were subsequently interpreted as adaptations that directly reflected coevolution (e.g., Howe 1977, Howe and Estabrook 1977, Stiles 1980, Herrera 1981, 1982). Recent studies of plant-disperser interactions, and numerous arguments oppose the earlier, overly "optimistic" view of mutual plant-disperser evolutionary adjustment (Janzen and Martin 1982, Wheelwright and Orians 1982, Herrera 1984a, c, 1985a, 1986, Howe 1984, Wheelwright 1985b). The present study 
is an attempt at critically evaluating the evolutionary potential of a plant-disperser interaction based on the analysis of patterns and consequences of individual variation in dispersal-related attributes (fruiting phenology, crop size, fruit characteristics).

Individual variation in net reproductive output as a direct consequence of dispersal-related traits is a necessary (albeit not sufficient) requisite for adaptive changes in these attributes to take place. Previous studies have documented individual variation of dispersalrelated traits in populations of vertebrate-dispersed species (e.g., Howe and De Steven 1979, Howe and Vande Kerckhove 1979, 1980, 1981, Howe 1980, 1983, Herrera 1984c, Courtney and Manzur 1985). Sometimes this variability correlated with differences in seed dispersal rates, and was used to support the notion that dispersal agents might have a selective influence on dispersal-related plant traits (and hence the evolutionary potential inherent to the plant-disperser interaction). In general, these studies, both field and theoretical (e.g., Howe and Estabrook 1977), failed to recognize the essential difference between the relative dispersal success associated with a given character state of a particular trait, and the success of the individual bearing it. Large fruits, for instance, may be at a relative dispersal advantage compared to small fruits, but it does not necessarily follow from this observation that large-fruited individuals ultimately derive a net reproductive advantage over small-fruited ones from having large fruits. The (proximate) success of a character state of a dispersal trait (relative to other character states) may not be construed as responsible for ultimate success of the individual exhibiting it, unless differential dispersal success of individuals due to variation in that trait actually translate into differential contributions to the population's realized reproductive output. Obvious as this may appear, the above misinterpretation has plagued evolutionary approaches to reproductive plant ecology, and it has been recently pointed out (although in slightly different terms) for phenological and pollination studies by Schmitt (1983), Zimmerman (1984), and Zimmerman and Gross (1984).

The present study not only examines individual variation in dispersal-related traits and how this influences seed dispersal, but also attempts to find out if dispersal variability actually explains individual differences in net seed output. $O$. quadripartita is particularly well suited to examine the relation between reproductive output and dispersal-related attributes, because it exhibits extreme levels of individual variation in a variety of dispersal traits.

\section{Plant Natural History}

Osyris quadripartita (Santalaceae) is an evergreen, root hemiparasitic, dioecious shrub up to $3 \mathrm{~m}$ in height occurring in a variety of Mediterranean-type scrublands. Its range includes the Canary Islands, northwest Africa, and the Iberian Peninsula (Jahandiez and Maire
1932, Quézel and Santa 1962, Bramwell and Bramwell 1974, Jalas and Suominen 1976). In Iberia, the species is almost restricted to coastal areas south of $40^{\circ} \mathrm{N}$, where it mostly occurs as small disjunct populations on sandy soils. The northern limits of its distributional range closely coincide with the $10^{\circ} \mathrm{C}$ mean January isotherm and the 350-d frost-free isoline. In southern Spain, $O$. quadripartita parasitizes evergreen and summer drought-deciduous shrubs of many species (C. M. Herrera, personal observation; see Ferrarini 1950 for the congeneric $O$. alba). General phenological patterns (Herrera 1984b) and the predispersal reproductive biology of females (Herrera 1985b) have been described, and further details on the species' natural history may be found in J. Herrera (1985). The flowering period lasts for nearly 6 mo (March-September) for females and nearly the entire year for males, with a peak in May-June for both sexes. The interval between anthesis and fruit ripening is quite variable (range 13-54 wk), due to within-plant variance in developmental rates. As a consequence, ripe fruits are produced throughout the year, with a major peak in winter and a minor one in spring. The growth season encompasses the period November-August for females and virtually the entire year for males.

\section{Study Site And Methods}

An individually marked population of $O$. quadripartita was intensively studied from October 1978 through April 1984 in a 3.5-ha plot in dense Mediterranean scrub on nearly level terrain near El Viso del Alcor (Sevilla Province, southern Spain, 37²6 N, 5⒋ W), at $100 \mathrm{~m}$ elevation. $O$. quadripartita accounts there for $6.1 \%$ of the woody plant cover. Details on the composition and ecology of vegetation at the site may be found in Herrera (1984a), and general descriptions of the region in Anonymous (1962) and Ministerio de Agricultura (1975). Climate is of the warm Mediterranean type. Average annual precipitation $(N=43 \mathrm{yr})$ is $613 \mathrm{~mm}$. On average, $76.4 \%$ of the annual precipitation falls in the period October-March. Mean monthly temperature of the coldest (January) and hottest (July) months are $10.5^{\circ}$ and $26.8^{\circ} \mathrm{C}$. The severe summer drought is the dominant stress on plants at the site. Winter cold stress is unimportant (Montero and González 1974, Herrera 1984a).

Fruiting phenology was investigated by means of regular observations (at intervals of 1-4 wk, usually 2-wk intervals) on 27 marked female shrubs (vandals damaged 3 plants and these were omitted from some analyses). Height, average diameter of vertical projection, and distance to the nearest reproductive male individual were measured for these plants. In this paper, phenological data for the period 9 April 1980-9 April 1984 (97 observation dates in total) were used. On each observation date, numbers of intact and damaged ripe fruits on the plants, and fallen fruits, were recorded. Damaged and fallen fruits were always re- 
moved to avoid duplication in subsequent counts, as these fruits ordinarily remain undispersed and may persist for long periods. Removal of some fruits by ants or rodents between consecutive sampling dates might have reduced fallen fruit estimates. Nevertheless, fruits experimentally placed on the ground beneath plants at various times of the year had an average persistence exceeding the average interval between fruit counts; thus the effect of missing fruits on the results is probably negligible. When plants were in bloom, the number of open flowers was estimated for each individual in 1981, 1982, and 1983. Only the length of the flowering period was recorded in 1980.

In 1980 and 1981, I periodically measured the diameter of ripe fruits on and beneath the study plants, and recorded their condition (intact or damaged). Samples of ripe fruits were collected at various times of year from study individuals and 10 plants not considered in this study to obtain statistics for fruit mass components. For these fruits I recorded, in addition to diameter, the wet mass of pulp, seed, and whole fruit. Four large samples of ripe fruits were collected from unmarked plants in March, May, October, and December in 1979 and 1980 . Fruits were dried at $40^{\circ}$ to constant mass, and pulp samples were prepared for chemical analyses. Soluble carbohydrates, neutral-detergent fiber, protein, lipids, and ash content were determined (methods as described in Herrera 1987).

$O$. quadripartita is bird-dispersed. Information on local avian frugivores was gathered during 1978-1982. Bird were trapped with mist-nets (total effort 1804 nethours, nets operated on a total of $40 \mathrm{~d}$ ). Feces obtained from the birds were examined (macro- and microscopically) to determine diet composition, with particular attention paid to the fruit component. Seeds and skins present in feces were used to identify fruit species. Further details on methods and a detailed account of avian frugivory and seed dispersal at the community level in the study locality may be found in Herrera $(1984 a)$.

The number of ripe fruits produced, hence actual crop sizes and fruit ripening rates, could not be determined for study plants because numbers of unripe fruits were not counted. Instead, numbers of fruits recorded on observation dates were used as the raw material for all analyses. For comparative purposes, using standing crop data as indirect estimates of fruit production is a valid procedure for $O$. quadripartita in the study locality, as supported by two independent lines of evidence. (1) In 1978-1979, detailed observations were conducted on the fruit production rates of a subset $(N=$ 12 ) of study plants, based on regular bi-weekly counts of ripe and unripe fruits on marked stems. It was possible to determine the number of ripe fruits actually produced in the dates preceding the count, along with the instantaneous standing crop. For all plants combined, there was a strong positive correlation between these variables $(r=0.852, N=12, P=.0003)$, indi- cating that standing crop size closely tracked fruit production rate. Separate correlations for individual plants were similarly significant, as were correlations across plants for different time periods. (2) For six plants intensively studied in 1980-1981 (Herrera 1985b), an almost perfect correlation existed between the estimated total number of ripe fruits produced by the plant over the whole season and its annual average standing $\operatorname{crop}(r=0.9992, N=6, P<.0001)$.

Descriptive statistics for circular distributions ("circular statistics" hereafter) have been used to characterize fruiting phenology and related traits quantitatively. More usual methods are unsuitable in cases such as this in which there is neither a beginning nor an end of the fruiting activity in the population that may be used to locate the zero point for the reference time scale. Phenological data have been treated as circular frequency distributions with data grouped at $30^{\circ}(=1$ mo) intervals. Computations and statistical tests are based on Zar (1984). There was some variation in the number of fruit counts conducted per calendar month (range 6-11, all years combined), and this could introduce some bias if raw count data were used in the analyses. For this reason, and unless otherwise stated, all analyses below are based on average monthly figures, obtained after grouping count data by month.

\section{RESULTS \\ Fruiting phenology}

Individual variation. - Most individuals produce fruits throughout the year (Fig. 1). Most plants have two fruiting peaks in the year, generally in spring and autumn-winter. For most plants $(N=14)$ the spring peak was lower, for three the two peaks were equivalent, and for three the major peak was in spring. The remaining plants (33\%) exhibited a single fruiting peak that occurred in autumn-winter. These phenological classes are quite broad and do not describe the virtually continuous gradation that occurs in the population. Mean angle ( $\bar{a}$, measuring central tendency) and mean vector $\left(r_{a}\right.$, measuring concentration) were obtained for each average fruiting cycle in Fig. 1. The centers of the fruiting period (CFP) of individual plants, as estimated by back-transforming mean angles to dates, occurred in May (two plants), and from September through March. Statistics for $r_{a}(\bar{X} \pm \mathrm{SD}=0.58 \pm 0.14, N=$ 27 , range $=0.25-0.81)$ also denote broad variation in the levels of seasonality ( $r_{a}$ theoretical range is $\left.0-1\right)$.

Annual variation in fruiting phenology.-Annual variation in fruiting phenology was examined by obtaining the circular statistics $\bar{a}$ and $r_{a}$ for individual plants (using monthly average fruit counts) in each of the four complete annual cycles studied. In these analyses, 9 April was used as the starting point for cycles. This procedure does not affect results, yet it has the advantage of dividing counts exactly into four $1-y r$ periods, and will be used throughout this paper. 


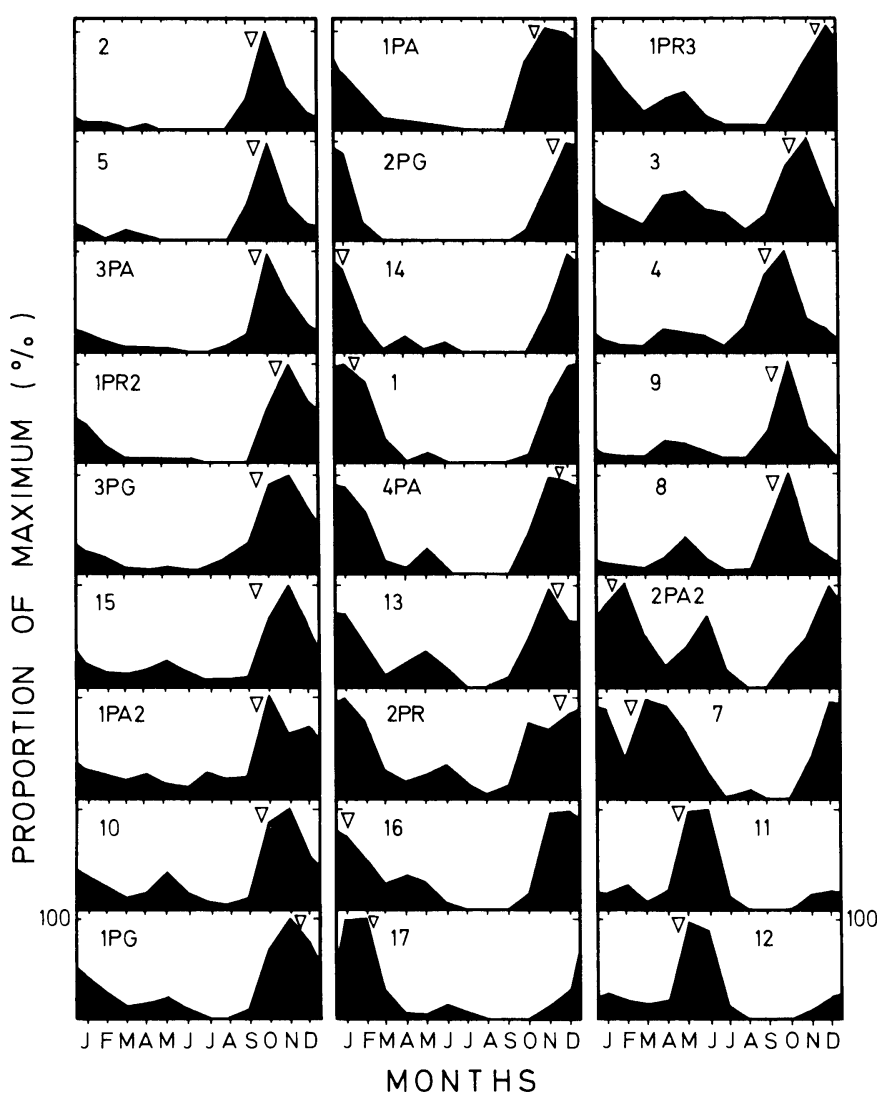

FIG. 1. Average fruiting cycles (1980-1984) of 27 individual Osyris quadripartita study plants. Codes in graphs identify individual plants. Cycles were obtained by computing means (all years combined) for the number of ripe fruits borne on individual plants on count dates, grouped by month. Monthly means were then divided by the plant yearly maximum and resulting figures expressed as percentages, hence yielding average "shapes" of cycles independent of crop sizes. Triangles ( $\nabla)$ above curves mark the centers of the respective fruiting cycles, obtained by back-transforming the mean angle for the circular distribution.

At the population level, $r_{a}$ did not vary significantly among years $(H=5.58, \mathrm{df}=3, P=.134$; KruskalWallis analysis of variance). The degree of seasonality in fruiting thus remained constant for the population over the 4-yr study period. In contrast, there was significant interannual heterogeneity in the mean $\bar{a}$ for the population $\left(F=20.88\right.$, df $=3,92, P<10^{-9}$; Watson-Williams test), indicative of variation in CFP at the population level. Paired comparisons of cycles for $\bar{a}$ demonstrate that the season 1983-1984 differed significantly from either of the three preceding ones considered individually $(P<.001$, Watson-Williams test). The first three seasons were not significantly heterogeneous in mean $\bar{a}(F=0.42$, df $=2,69, P=.661$, Watson-Williams test). Back-transforming mean $\bar{a}$ to dates, the mean CFP's for the population were 15 October (1980-1981), 27 October (1981-1982), 6 November (1982-1983), and 6 April (1983-1984).

The significant change in mean CFP for the population in 1983-1984 was due to a modification in the seasonal behavior of a substantial fraction of the "autumn-winter" plants (Fig. 2). Among the 21 plants predominantly fruiting in autumn-winter in 19801983, 12 shifted to predominantly spring fruiting in 1983-1984. The three plants predominantly fruiting in spring in 1980-1983 continued to do so in 19831984. Thus some individuals vary with regard to interannual constancy in fruiting schedules. The difference between extreme annual values of CFP for individual plants over 1980-1984 ranges from 0.3 to 5.3 mo (the upper limit of this statistic is $6 \mathrm{mo}$ ). The frequency distribution of these differences does not depart from a uniform distribution (chi-square $=1.00, \mathrm{df}=$ $5, P=.962$ ). All the possible degrees of interannual variability in CFP are thus represented, and in similar proportions, in the study population.

\section{Crop size}

Individual and annual variation. - For all years, frequency distributions of "annual average standing crops" (ASC hereafter) are strongly skewed to the right (Fig. 3) $(\mathrm{ASC}=$ the mean value of monthly averages for standing ripe fruit counts in a given year). The number of ripe fruits (averaged over a year) was very small for 


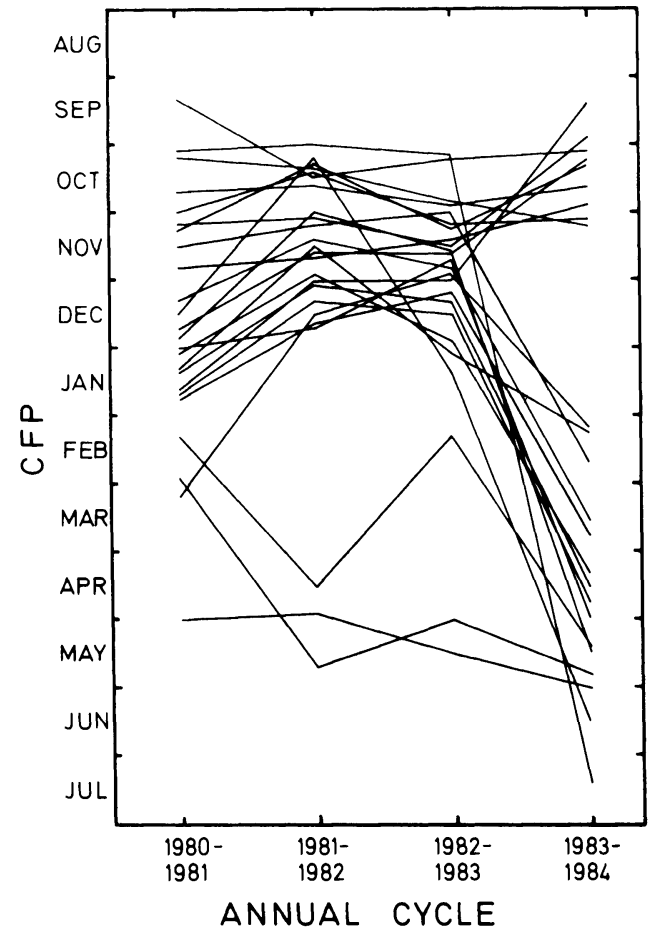

FIG. 2. Annual variation in the center of the fruiting period (CFP) of Osyris quadripartita study plants. Each line corresponds to a single individual. CFP for each plant was estimated by back-transforming to a date the mean angle of the circular distribution of fruiting events.

the majority of individuals, with a few plants having substantially greater standing crops. Medians of distributions are 5.4 (1980-1981), 3.9 (1981-1982), 7.4 (1982-1983), and 1.9 (1983-1984) fruits.

There was significant interannual heterogeneity in ASC $(H=17.78, \mathrm{df}=3, P=.0005$; Kruskal-Wallis test). Paired comparisons of annual cycles demonstrate that the 1983-1984 season differed significantly from each of the three preceding ones considered individually $(P<.02$ or better). ASC was not significantly heterogeneous among the first three seasons $(H=3.55$, $\mathrm{df}=2, P=.169)$. Average standing crops thus decreased significantly in 1983-1984.

Interindividual differences in ASC remained consistent from year to year. Extreme ASC values were consistently exhibited by the same plants (Fig. 3). For all possible between-year pairwise contrasts, there was significant rank correlation between the ASC's of individual plants in different years $\left(r_{s}=0.624-0.873, N=\right.$ 27 in all cases, $P<.001$ or better). Although absolute ASC values fluctuated between years, crop size of a given plant relative to others in the population tended to remain invariant.

Correlates of individual variation. - Five potential sources of individual variation in crop size were examined: plant height $(\mathrm{PH})$, average diameter of shrub's vertical projection (AD), length of the flowering period
(LFL), number of open flowers averaged over the flowering period (NFL; not available for 1980-1981), and distance to the nearest reproductive male plant (DNM). These were used as independent variables, and standing crop size (ASC) as the dependent one, in multiple stepwise regression analyses. Separate regressions were run for the 1981-1982, 1982-1983, and 1983-1984 data, and for the 4 -yr average figures. No analyses could be performed on the 1980-1981 data due to missing NFL values.

NFL is the first significant variable entering regression equations for the 1981-1982, 1982-1983, and 4-yr average data sets, and the second variable entering the 1983-1984 regression (Table 1). LFL is the first significant variable in 1983-1984, and AD the second significant variable in 1981-1982. Neither PH nor DNM contributed significantly to $R^{2}$ in any of the analyses. The number of flowers, rather than the duration of flowering (among the traits considered here), explained most of individual variation in standing crop

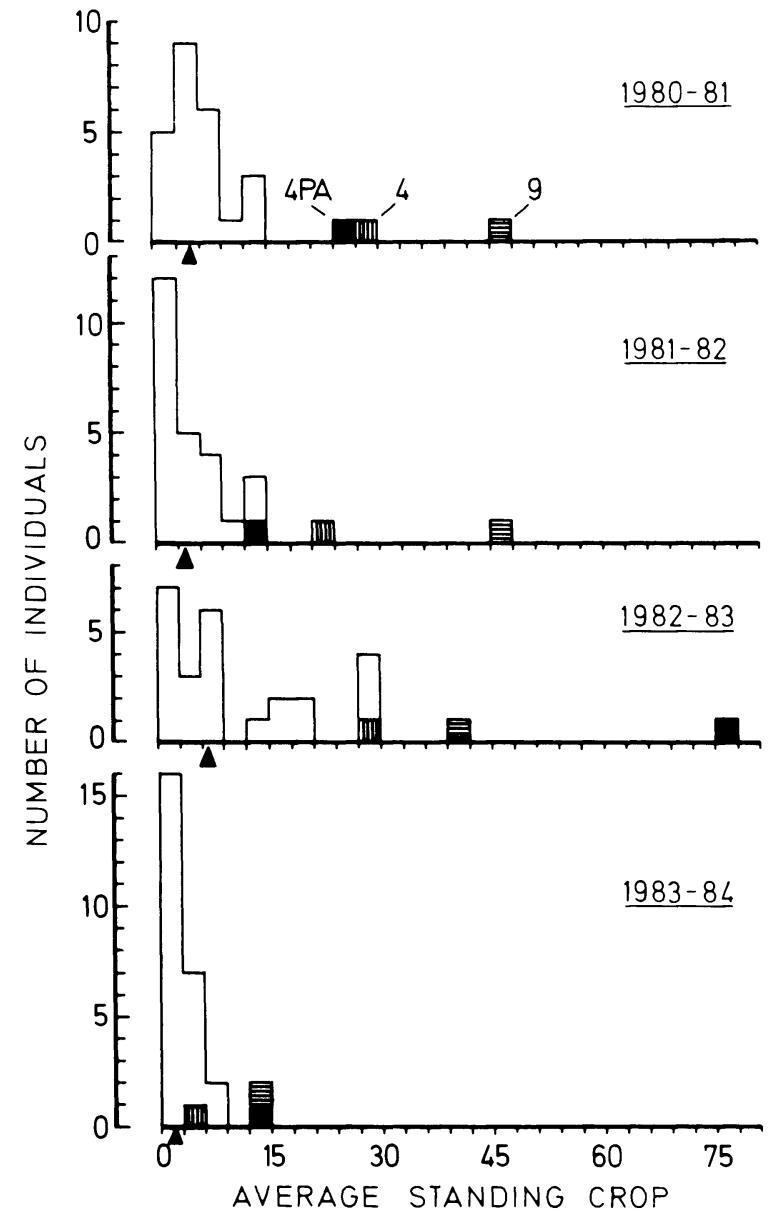

FIG. 3. Frequency distributions of annual average standing crops of ripe fruits in the four study seasons. Triangles (A) mark the medians of distributions. Filled or shaded boxes indicate the position of three selected individuals in different years. 
size in two out of three years. The contribution of NFL to $R^{2}$ steadily declined from 1981-1982 (0.636) through 1982-1983 (0.188) to 1983-1984 (0.098), indicating that the variance in ASC explained by flower number was variable over the study period. With the exception of 1981-1982, the predictive value of the independent variables considered here (as judged from $R^{2}$ ) is fairly small; thus variables not included here are responsible for most individual variation in ASC.

Individual differences in plant size, as estimated by either AD or PH, have very little (AD in 1981-1982) or no influence on differential crop sizes. In all data sets, $\mathrm{AD}$ and $\mathrm{PH}$ are not correlated $(P>.05)$ with either NFL or LFL. The total number of flowers, and eventually fruits, produced by a plant is therefore not significantly related to its size.

Correlates of annual variation. - Despite the significant annual variation in crop size shown earlier, flower number (NFL), the variable most closely related to ASC, did not change among years $(H=1.69$, df $=2$, $P=.429 ;$ Kruskal-Wallis test, 1981-1982, 1982-1983 and 1983-1984 data). This suggests that annual variation in crop size depends more on the proportion of fruits initiated than on the number of flowers produced.

The most critical phase in fruit development is the rather abrupt transition from the $3 \mathrm{~mm}$ diameter ovary to the much larger unripe fruit; most developing fruits go through this developmental phase during the summer drought (Herrera 1985b). Correlations were run with all $4 \mathrm{yr}$ combined, between total rainfall in the period July-September and the mean ASC for the population in the subsequent season. Correlations for both untransformed $(r=0.978, P=.024)$ and log-transformed ( $r=0.989, P=.009)$ data are statistically significant. Variation in summer rainfall, through its influence on fruit development, explains much of the annual variation in ASC at the population level.

\section{The ripe fruit}

Size, structure, and chemical composition. - The fruits of $O$. quadripartita are nearly spherical one-seed drupes, which, when ripe, range in color from light yellowishorange to red. Color variation is mainly associated with season of ripening; spring and summer fruits tend to be redder. The diameter of ripe fruits ranged between 4.8 and $11.0 \mathrm{~mm}(\bar{X} \pm \mathrm{SD}=7.18 \pm 0.77 \mathrm{~mm}, N=$ 3201 fruits from 37 plants combined), and their fresh mass between 95 and $890 \mathrm{mg}(267 \pm 107 \mathrm{mg}, N=528$ fruits, 23 plants). Fresh mass of single (apparently viable) seeds ranged between 24 and $232 \mathrm{mg}(86 \pm 29$ mg, $N=527$ fruits, 23 plants), and that of the pulp from 58 to $657 \mathrm{mg}(181 \pm 83 \mathrm{mg}, N=527$ fruits, 23 plants). The pulp represented between 42.4 and $83.1 \%$ of the fresh mass of individual ripe drupes (66.5 \pm $6.7 \%, N=527$ fruits, 23 plants).

Pulp mass $(P M)$ was linearly correlated with seed mass $(S M)$ (regression equation $P M=2.150 S M-$ $0.0037 ; r=0.760, N=527, P<.001)$. Seed mass
$\left(\mathrm{CV}=33.7 \%, \mathrm{SE}_{\mathrm{CV}}=1.1 \%\right)$ was less variable than $P M$ $\left(\mathrm{CV}=45.9 \%, \mathrm{SE}_{\mathrm{CV}}=1.7 \%\right)$. Variation in $P M$ explains $96.8 \%$ of variance in total fruit mass $(r=0.984, N=$ $527)$, while seed mass explains only $74.5 \%(r=0.863$, $N=527)$. Variation in pulp mass explains $90.3 \%$ of variance in fruit diameter $(r=0.950, N=527)$, while seed mass explains only $64.2 \%(r=0.801, N=528)$. Variation in the amount of pulp per fruit was therefore more directly responsible than variation in seed size in accounting for observed variation in fruit size. Furthermore, fruit size, as estimated by its diameter, was a very reliable predictor of internal structure, and particularly of the absolute mass of pulp. (All the preceding correlations and regressions were run on untransformed data. Logarithmic transformation of mass variables did not significantly improve $R^{2}$ in any case.)

Water represented, on average, $78.4 \%$ of fresh pulp. The dry pulp was mostly "soluble" carbohydrates $(77.6 \pm 2.6 \%$ dry mass, $N=4)$. Protein $(7.1 \pm 0.9 \%$, $N=4)$, ash (6.6 $\pm 0.9 \%, N=5)$, neutral-detergent fiber $(6.2 \pm 2.1 \%, N=4)$ and lipids $(2.2 \pm 0.8 \%, N=4)$ were relatively minor constituents (samples for analyses collected at different times of year). Relative to the pulp of an "average" southern Spanish fleshy fruit (Herrera 1987), the pulp of $O$. quadripartita is comparatively rich in protein and minerals, and poor in lipids.

Individual variation. - Individual plants differed greatly in fruit characteristics. One-way analyses of variance demonstrate highly significant interindividual differences for all variables considered $(P<.0001)$.

Mean fruit size tended to be more constant among plants than either seed or pulp mass. Average fruit diameter of individual plants ranged between 6.1 and $9.3 \mathrm{~mm}\left(\mathrm{CV}=10.7 \%, \mathrm{SE}_{\mathrm{CV}}=1.3 \%\right)$, seed mass between 49 and $146 \mathrm{mg}\left(\mathrm{CV}=25.6 \%, \mathrm{SE}_{\mathrm{CV}}=4.0 \%\right)$, and pulp mass between 100 and $343 \mathrm{mg}\left(\mathrm{CV}=32.0 \%, \mathrm{SE}_{\mathrm{CV}}=\right.$ $5.2 \%$ ) (Fig. 4). Individual differences in the amount of pulp mass per fruit explain $96.8 \%$ of variance in fruit mass ( $r=0.984, N=23)$, whereas seed mass explains only $77.8 \%(r=0.882, N=23)$.

Plants differed significantly in the relative amounts of pulp and seed biomass in individual drupes, as demonstrated by covariance analysis of the 23 regression equations relating pulp to seed mass for individual plants $(F=11.65, \mathrm{df}=22,503, P<.0001)$. Regression slopes range between 0.69 and 6.89 , indicating broad individual variation in the amount of pulp allocated to a seed mass unit. This variation is independent of individual differences in average seed mass. The pulp/ seed mass balance may favor either pulp (regression slope $>1$ ) or seed (slope $<1$ ) mass.

Seasonal variation. - The size of fruits, and the mass of their component parts, varied seasonally (Table 2) (analysis of variance; $P<.00001$ in all cases). Monthly averages for fruit diameter, the variable most thoroughly sampled, ranged between 6.8 and $7.7 \mathrm{~mm}$ (Table 2). Fruits ripening in winter (January-March) tend- 
TABLE 1. Variables producing significant increases in $R^{2}(P<$ .05 or better), and order in which they enter the equation, in multiple stepwise regressions having average standing crops of ripe fruits as the dependent variable. $N=24$ plants in all analyses.

\begin{tabular}{cccccc}
\hline \hline & \multicolumn{2}{c}{ 1st step } & & \multicolumn{2}{c}{ 2nd step } \\
\cline { 2 - 3 } \cline { 5 - 6 } Data set & $\begin{array}{c}\text { Inde- } \\
\text { pendent } \\
\text { vari- } \\
\text { able* }\end{array}$ & $\begin{array}{c}\text { In- } \\
\text { crease } \\
\text { in } R^{2}\end{array}$ & & $\begin{array}{c}\text { Inde- } \\
\text { pendent } \\
\text { vari- } \\
\text { able* }\end{array}$ & $\begin{array}{c}\text { In- } \\
\text { crease } \\
\text { in } R^{2}\end{array}$ \\
\hline $1981-1982$ & NFL & 0.636 & & AD & 0.052 \\
$1982-1983$ & NFL & 0.188 & & $\cdots+$ & $\ldots$ \\
$1983-1984$ & LFL & 0.281 & & NFL & 0.098 \\
4-yr averages & NFL & 0.509 & $\cdots$ & $\cdots$ \\
\hline
\end{tabular}

* NFL $=$ number of open flowers averaged over the flowering period. $A D=$ diameter of shrub's vertical projection. LFL $=$ length of the flowering period.

$\dagger$ No independent variable entering the regression model at the second step produces a significant increase in $R^{2}$.

ed to be smaller than those produced during the rest of the year. Variation in mass variables was consistent with this pattern, although adequate information was available only for 4 mo (Table 2). The heaviest fruits, having the largest seeds and amounts of pulp, were produced in May. Fruits produced in autumn and winter had similarly small seeds, but they differed in the amount of pulp per fruit. October fruits had more pulp than November and January fruits. Pulp mass ( $\mathrm{CV}=$ $29.6 \%, \mathrm{SE}_{\mathrm{CV}}=11.3 \%$ ) tended to be seasonally more variable than seed mass $\left(\mathrm{CV}=15.8 \%, \mathrm{SE}_{\mathrm{CV}}=5.7 \%\right)$.

There was also seasonal variation in the pulp/seed mass ratio. Regressions of pulp mass $(P M)$ with seed mass $(S M)$ were calculated separately for January $(P M=$ $1.026 S M+0.046 ; r=0.665)$, May $(P M=1.862 S M+$ $0.031 ; r=0.709)$, October $(P M=2.819 S M-0.030$; $r=0.836)$, and November $(P M=1.228 S M+0.030$; $r=0.451$ ) (sample sizes as in Table 2). An analysis of covariance demonstrates significant heterogeneity among the regressions $(F=33.98, \mathrm{df}=3,509, P<$ $.00001)$. The amount of pulp per unit seed mass tended to be lowest in November and January, highest in Oc-

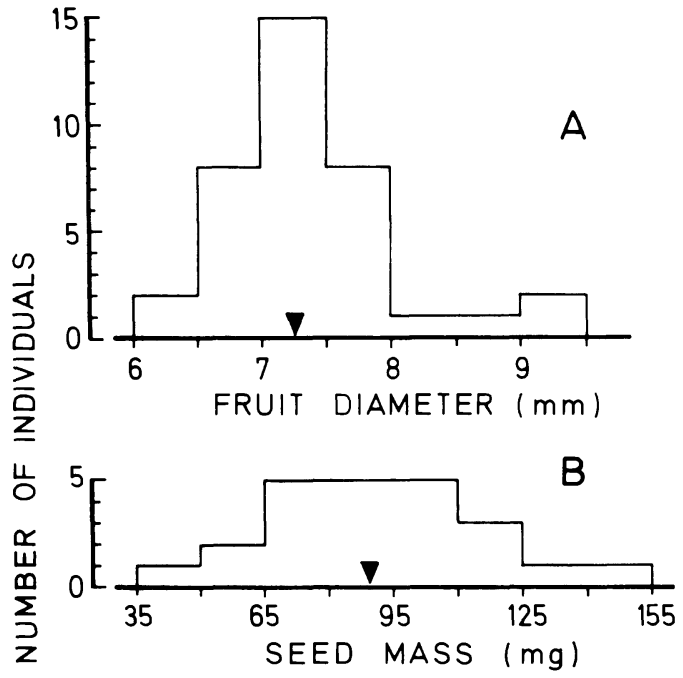

C

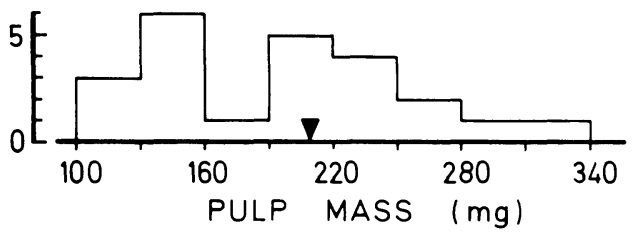

FIG. 4. Frequency distributions of average fruit characteristics for individual plants. Triangles $(\boldsymbol{\nabla})$ mark the medians of distributions. Seed and pulp masses refer to fresh material. Sample sizes are: A, 37 plants (3201 fruits in total); B, 23 plants (528 fruits); C, 23 plants (527 fruits).

tober, and intermediate in May. Seed and pulp masses varied independently, and in combination produced a third and different seasonal pattern in the pulp/seed mass ratio.

Seasonal variation in fruit characteristics may result from differential fruit features of plants differing in fruiting phenology, or from intra-plant variation in the characteristics of fruits produced at different times of

TABLE 2. Seasonal variation in the characteristics of Osyris quadripartita fruits (all plants and years combined). Means in the same row sharing a superscript letter are not statistically different $(P>.05$, Student-Newman-Keuls test). Masses refer to fresh material.

\begin{tabular}{|c|c|c|c|c|c|c|c|c|c|c|c|}
\hline & & Jan & Feb & Mar & May & Jun & Aug & Sep & Oct & Nov & Dec \\
\hline $\begin{array}{l}\text { Fruit diameter } \\
\quad(\mathrm{mm})\end{array}$ & $\begin{array}{l}\bar{X} \\
\text { SD } \\
N\end{array}$ & $\begin{array}{c}6.98^{\mathrm{a}} \\
0.56 \\
252\end{array}$ & $\begin{array}{l}6.89^{\mathrm{a}, \mathrm{b}} \\
0.54 \\
185\end{array}$ & $\begin{array}{l}6.78^{\mathrm{b}} \\
0.56 \\
78\end{array}$ & $\begin{array}{c}7.70^{c} \\
0.77 \\
491\end{array}$ & $\begin{array}{l}7.28^{\mathrm{d}} \\
0.66 \\
101\end{array}$ & $\begin{array}{l}7.39^{\mathrm{d}} \\
0.86 \\
34\end{array}$ & $\begin{array}{c}6.93^{\mathrm{a}} \\
0.76 \\
187\end{array}$ & $\begin{array}{c}7.39^{\mathrm{d}} \\
0.85 \\
276\end{array}$ & $\begin{array}{c}7.06^{\mathrm{e}} \\
0.71 \\
1444\end{array}$ & $\begin{array}{r}7.30^{\mathrm{d}} \\
0.88 \\
153\end{array}$ \\
\hline $\begin{array}{l}\text { Fruit mass } \\
\quad(\mathrm{mg})\end{array}$ & $\begin{array}{l}\bar{X} \\
\text { SD } \\
N \\
-\end{array}$ & $\begin{array}{c}201^{\mathrm{a}} \\
54 \\
49\end{array}$ & $\ldots *$ & $\ldots$ & $\begin{array}{l}322^{\mathrm{b}} \\
109 \\
188\end{array}$ & $\ldots$ & $\ldots$ & $\ldots$ & $\begin{array}{r}256^{c} \\
90 \\
172\end{array}$ & $\begin{array}{c}195^{\mathrm{a}} \\
52 \\
107\end{array}$ & $\cdots+$ \\
\hline $\begin{array}{l}\text { Seed mass } \\
(\mathrm{mg})\end{array}$ & $\begin{array}{l}\bar{X} \\
\text { SD } \\
N\end{array}$ & $\begin{array}{l}77^{a} \\
23 \\
49\end{array}$ & $\ldots$ & $\ldots$ & $\begin{array}{l}101^{\mathrm{b}} \\
32 \\
187\end{array}$ & $\cdots$ & $\cdots$ & $\cdots$ & $\begin{array}{c}75^{a} \\
21 \\
172\end{array}$ & $\begin{array}{r}74^{a} \\
16 \\
107\end{array}$ & $\cdots \dagger$ \\
\hline $\begin{array}{l}\text { Pulp mass } \\
\text { (mg) }\end{array}$ & $\begin{array}{l}\bar{X} \\
\text { SD } \\
N\end{array}$ & $\begin{array}{c}124^{\mathrm{a}} \\
36 \\
49\end{array}$ & $\cdots$ & $\ldots$ & $\begin{array}{c}220^{b} \\
84 \\
187\end{array}$ & $\ldots$ & $\cdots$ & $\ldots$ & $\begin{array}{c}181^{\mathrm{c}} \\
72^{2} \\
172\end{array}$ & $\begin{array}{c}121^{\mathrm{a}} \\
43 \\
107\end{array}$ & $\cdots+$ \\
\hline
\end{tabular}

* No fruit were sampled for mass measurements in that month.

$\dagger$ Sample sizes too small for separate analysis $(N=12)$. 
TABLE 3. Frequency of occurrence (\%) of Osyris quadripartita fruit remains in fecal samples of the frugivorous birds that disperse their seeds at the study site. In parentheses, number of fecal samples examined per species and month.

\begin{tabular}{|c|c|c|c|c|c|c|c|c|c|}
\hline & Jan & Feb & Mar & Apr & May & Jun & Jul & Aug & Sep \\
\hline Erithacus rubecula & $\begin{array}{c}0 \\
(22)\end{array}$ & $\begin{array}{c}25.0 \\
(8)\end{array}$ & $\begin{array}{c}0 \\
\text { (7) }\end{array}$ & $\begin{array}{c}0 \\
(1)\end{array}$ & & & & & \\
\hline Turdus merula & $\begin{array}{c}0 \\
(3)\end{array}$ & & $\begin{array}{c}0 \\
(1)\end{array}$ & & $\begin{array}{r}100 \\
\text { (1) }\end{array}$ & $\begin{array}{l}60.0 \\
(5)\end{array}$ & & $\begin{array}{c}0 \\
(3)\end{array}$ & $\begin{array}{l}25.0 \\
(4)\end{array}$ \\
\hline Sylvia atricapilla & $\begin{array}{l}41.8 \\
(55)\end{array}$ & $\begin{array}{l}50.0 \\
(24)\end{array}$ & $\begin{array}{c}30.8 \\
(13)\end{array}$ & $\begin{array}{l}40.0 \\
(10)\end{array}$ & & & $\begin{array}{r}100 \\
\text { (2) }\end{array}$ & & $\begin{array}{c}75.0 \\
(4)\end{array}$ \\
\hline Sylvia borin & & & & $\begin{array}{l}66.7 \\
(3)\end{array}$ & $\begin{array}{l}20.0 \\
(5)\end{array}$ & & & & $\begin{array}{l}25.0 \\
(24)\end{array}$ \\
\hline Sylvia communis & & & & & & & & $\begin{array}{c}0 \\
(3)\end{array}$ & $\begin{array}{l}19.2 \\
(26)\end{array}$ \\
\hline Sylvia melanocephala & $\begin{array}{c}3.8 \\
(26)\end{array}$ & $\begin{array}{c}7.1 \\
(14)\end{array}$ & $\begin{array}{c}0 \\
(8)\end{array}$ & $\begin{array}{c}0 \\
(22)\end{array}$ & $\begin{array}{c}0 \\
(12)\end{array}$ & $\begin{array}{c}4.9 \\
(41)\end{array}$ & $\begin{array}{c}0 \\
(16)\end{array}$ & $\begin{array}{c}0 \\
(23)\end{array}$ & $\begin{array}{c}7.9 \\
(38)\end{array}$ \\
\hline Phoenicurus phoenicurus & & & & $\begin{array}{c}0 \\
(5)\end{array}$ & & & & & $\begin{array}{l}25.0 \\
(4)\end{array}$ \\
\hline Ficedula hypoleuca & & & & & & & & & $\begin{array}{c}8.3 \\
(12)\end{array}$ \\
\hline
\end{tabular}

* Frequency of occurrence of all local fleshy fruit species combined.

year. Similarly, individual differences reported in the preceding section may be an indirect consequence of different fruiting phenologies being associated with different fruit characteristics. To separate the influence of seasonal and individual variation, two-way analyses of variance were conducted using plants and seasons ("spring" and "autumn-winter") as categorizing factors. Only the 10 individuals with sufficient seasonal data were used. Separate analyses were conducted for fruit diameter, fruit mass, pulp mass, and seed mass. The four analyses yielded highly significant results $(P<$ $.00001)$ for both plant and season factors, and for the plant $\times$ season interaction. This demonstrates that (1) there was within-plant seasonal variation in fruit characteristics; (2) individual differences found were not an indirect consequence of fruiting phenologies; and (3) there was significant interplant heterogeneity in the pattern of seasonal change in fruit characteristics.

Annual variation. - There was significant annual variation in fruit size for the fruits produced in some months, but not for others. Comparative fruit diameter data were available for May, October, and November of 1980 and 1981 ( $N=2211$ fruits). A two-way analysis of variance (year $\times$ month) indicates that, in addition to the month effect, the year $(F=82.89, P<.0001)$ and interaction $(F=14.65, P<.0001)$ effects are also highly significant. In all months considered here, average fruit diameter decreased from 1980 to 1981 , significantly so in October (7.71 and $7.12 \mathrm{~mm})$ and November ( 7.31 and $6.88 \mathrm{~mm}$ ), but not in May $(7.74$ and $7.69 \mathrm{~mm})$.

Annual variation in average fruit size of single plants could be examined for eight individuals ( $N=802$ fruits). Two-way analysis of variance (year $\times$ plant) of fruit size reveals a significant interaction effect $(F=3.18$, $P=.0025$ ) (in addition to the significant year and plant effects). Individuals thus differ in patterns of annual variation. Mean fruit diameter did not change between years in three plants ( $t$ tests, $P>.20$ in all cases), and decreased significantly from 1980 to 1981 in five individuals $(P<.01)$.

The fate of ripe fruits. $-\mathrm{A}$ ripe fruit may either be ingested by an appropriate seed dispersal agent or not. At the study site there were three major reasons for a ripe $O$. quadripartita fruit not to be eaten: (1) destruction or serious damage by invertebrates and/or rot; (2) falling to the ground, or being seriously damaged (e.g., pulp partly removed) as a direct consequence of handling by frugivorous birds; and (3) desiccation of the pulp before a frugivorous bird found it.

Invertebrates that damage ripe fruits include the cydnid bug Sehirus melanopterus, ants (including Aphaenogaster senilis, Plagiolepis pygmaea and Formica sp.), the tettigoniid grasshopper Odontura spinulicauda, and unidentified species of acridid grasshoppers and microlepidopteran larvae. The grasshoppers feed on pulp and seed, while all the others eat only the pulp. The activity of pulp-feeding species is generally followed by the rapid deterioration of the remaining pulp (desiccation in summer, rot at other times). Frugivorous birds may damage ripe fruits by (1) removing some pulp or skin during unsuccessful attempts at removal; (2) accidentally dropping them during manipulation; or (3) actively rejecting them. Ripe fruits beneath plants often exhibit characteristic "beak marks" (Manzur and Courtney 1984) suggestive of rejection. Fruits on the plant eventually dry up (summer) or rot, while dropped or rejected fruits commonly are fed upon by ants (mostly in spring-summer) and rodents.

\section{Seed dispersal: general patterns of avian frugivory}

At the study site, seeds of $O$. quadripartita were dispersed by eight species of frugivorous birds, which ate 
TABle 3. Continued.

\begin{tabular}{cccccc}
\hline \hline & & & \multicolumn{3}{c}{ All months } \\
\cline { 4 - 6 } Oct & Nov & Dec & Osyris & All* & Ratio \\
\hline 3.2 & 4.1 & 4.2 & 4.2 & 83.9 & 0.05 \\
$(31)$ & $(49)$ & $(24)$ & $(142)$ & & \\
26.7 & 20.0 & 0 & 25.0 & 86.0 & 0.29 \\
$(15)$ & $(10)$ & $(2)$ & $(44)$ & & \\
40.6 & 29.9 & 28.1 & 36.7 & 98.7 & 0.37 \\
$(64)$ & $(87)$ & $(57)$ & $(316)$ & & \\
25.0 & & & 27.8 & 88.9 & 0.31 \\
$(4)$ & & & $(36)$ & & \\
0 & & & 16.1 & 88.2 & 0.18 \\
$(2)$ & & & $(31)$ & & \\
4.7 & 2.0 & 0 & 3.1 & 79.1 & 0.04 \\
$(43)$ & $(49)$ & $(27)$ & $(319)$ & & \\
4.8 & & & 6.7 & 73.3 & 0.09 \\
$(21)$ & & & $(30)$ & & \\
0 & & & 7.1 & 35.7 & 0.20 \\
$(2)$ & & & $(14)$ & & \\
\hline
\end{tabular}

the ripe drupes and defecated or regurgitated the seeds intact (Table 3). These included two year-round residents (Turdus merula, Sylvia melanocephala), two fall migrants (Sylvia communis, Ficedula hypoleuca), two spring and fall migrants (Phoenicurus phoenicurus, Sylvia borin), and two overwintering species (Erithacus rubecula, Sylvia atricapilla). Size extremes were represented by the 12 -g body mass of $S$. melanocephala (average mouth width $7.1 \mathrm{~mm}$ ) and the $85-\mathrm{g} T$. merula (mouth width $13.4 \mathrm{~mm}$ ). The remaining species fell between 15.5 and $19.0 \mathrm{~g}$ body mass (mouth 7.9-8.6 $\mathrm{mm})$.

T. merula, $S$. atricapilla, and $S$. borin were the species that most often included $O$. quadripartita fruits in their diets, as judged from frequencies of occurrence in fecal samples (25.0-36.7\%, all months combined, Table 3). The frequency of $O$. quadripartita fruits in the diet of a bird species is not correlated with the proportion of fruits in the diet, all plant species combined $(r=0.573$, $N=8, P=.138$ ), which undoubtedly reflects the feeding preferences of the various species. The ratio of the frequency of $O$. quadripartita fruits to all fruit species may be used as a rough indication of this preference (Table 3). This ratio is greatest for T. merula, S. atricapilla, and $S$. borin. The proportional contribution of $O$. quadripartita to the total number of fruits ingested is also greatest for these species $(31.8,13.3$ and $18.6 \%$ of fruits, respectively; Herrera 1984a: Table 4).

Fruits of $O$. quadripartita were eaten by birds throughout the year (Table 3). At least two species were always locally present, the number increasing to 7-8 species in September-October. The abundance of dispersers experienced strong seasonal variation, with a marked maximum in November-January and a minimum in April-July (Fig. 5A). Disperser abundance and consumption of $O$. quadripartita fruits did not vary synchronously in the course of the year $(r=0.462$,
$N=12, P=.131)$. The frequency of $O$. quadripartita fruits in bird feces was highest in January-February (22.6-32.6\%) and, with the exception of August, remained relatively stable around moderate values (10.919.2\%) for the remainder of the year (Fig. 5B). As the number of fecal samples per species and month virtually coincided with the number of captures, monthly values for the overall frequency of $O$. quadripartita occurrence (all bird species combined) approached a weighted mean. The product of disperser abundance and the overall frequency of occurrence may therefore be used as an index of $O$. quadripartita consumption intensity (CI) by the disperser assemblage (Fig. 5C). CI is highest in January-February, and lowest in AprilAugust. A "high-demand" (September through February) and a "low-demand" (March through August) phase may clearly be distinguished in the annual cycle (Fig. 5).

\section{Dispersal failure}

In addition to intact fruits (no apparent sign of deterioration), "spoiled" (=dry + rotting + bird-damaged + invertebrate-damaged ripe fruits borne on the plant $)$ and "fallen" (=damaged + undamaged + beakmarked fruits lying on the ground under the plant) fruit categories have been considered in the analyses below. Categories had to be pooled because often it was difficult to attribute dispersal failure to a particular cause (e.g., the aspect of fruits with the pulp partly removed by ants is often similar to that of some bird-damaged

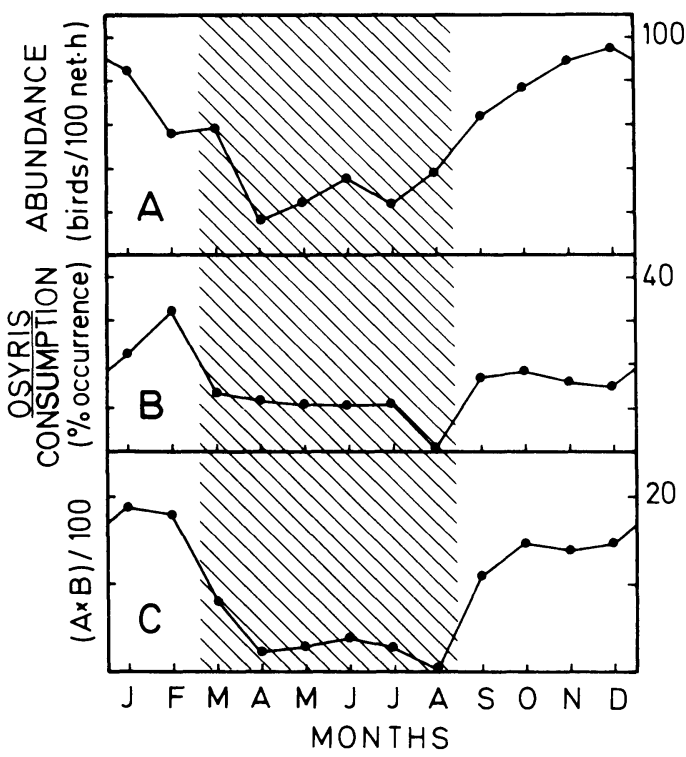

FIG. 5. Monthly variation in total abundance of $O$. quadripartita avian dispersers (A; determined from mist-net captures), frequency of ingestion of Osyris fruits by all disperser species combined (B; frequency of occurrence in fecal samples), and "consumption intensity" (C). The "low-demand" period on Osyris fruits is shaded, determined by examination of the position of each month in relation to the medians of distributions of the three parameters considered. 

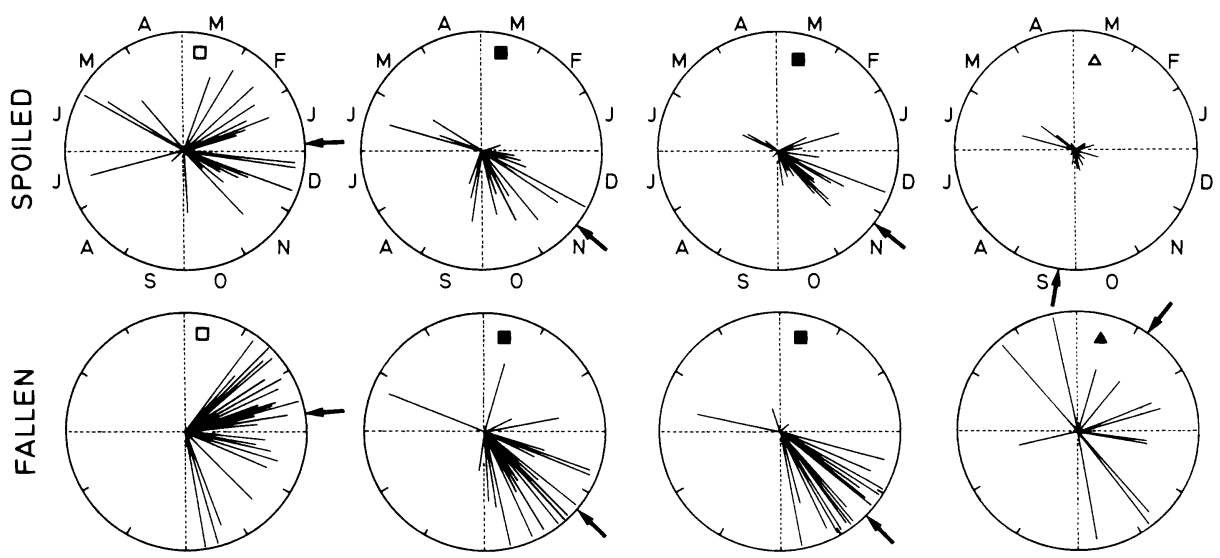

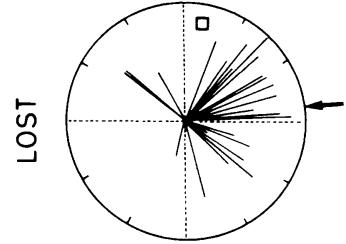

$\underline{1980-81}$

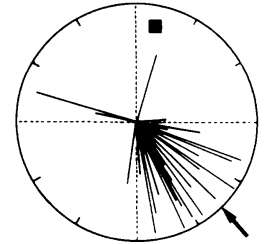

$1981-82$

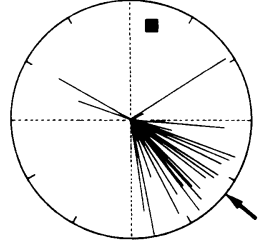

$\underline{1982-83}$

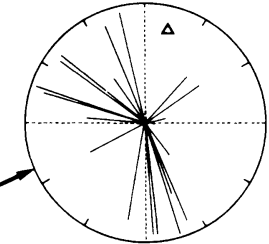

$1983-84$

Fig. 6. Variation in the temporal occurrence of various categories of undispersed fruits (spoiled $=$ dry + rotting + birddamaged + invertebrate-damaged ripe fruits borne on the plant; fallen $=$ damaged + undamaged + beak-marked fruits lying on the ground under the plant; lost = sum of fallen plus spoiled). Shown are the distributions of individual plants on a circular scale (=1 year; letters surrounding circles indicate months), using mean angle and mean vector as coordinates (in each graph, each radiating line represents a single plant). Arrows on perimeter of circles denote the population mean angle. Distributions sharing the same geometric symbol at the top of the graph are not significantly different in mean angle $(P>.10)$.

fruits). Total fruits "lost" are obtained by summing fallen and spoiled fruits.

Seasonal patterns: absolute fruit numbers. - Circular statistics $\left(r_{a}, \bar{a}\right)$ were obtained for the temporal distributions of spoiled, fallen, and lost fruits of individual plants in each annual cycle (Fig. 6). Individuals differed markedly with regard to central tendency $(\bar{a})$ in the occurrence of fruit categories. In any given year, extreme plants could differ by as much as 6 mo in the mean date of occurrence of spoiled or fallen fruits, although most individuals fell within a relatively narrow 3-4 mo range.

For each of the first three seasons, there are no statistically significant differences in mean population $\bar{a}$ among spoiled, fallen, and lost fruits (Watson-Williams test, $P>.65$ in all cases; Fig. 6). For 1983-1984, the mean population $\bar{a}$ values for spoiled (September) and fallen (February) fruits do differ significantly $(F=54.53$, df $=1,39, P<10^{-9}$ ), indicative of different seasonal courses of these two fruit categories at the population level.

There is significant heterogeneity among years in mean population $\bar{a}$ for spoiled $(F=4.83, \mathrm{df}=3,103$, $P=.0037)$, fallen $(F=13.27, \mathrm{df}=3,84, P<.0001)$, and lost $(F=9.09$, df $=3,97, P<.0001)$ fruits (Fig. 6). The 1981-1982 and 1982-1983 seasons did not differ significantly, and both differed from either 1980 1981 or 1983-1984. The latter two seasons differed significantly. For most plants, fruit losses were highest in December-January in 1980-1981, November (19811982 and 1982-1983), and September (spoiled) or February (fallen) in 1983-1984. In this latter season, the mean date for lost fruits occurred in late July (Fig. 6).

Seasonal patterns of fruit loss were not consistently related to temporal variation in standing crop sizes. In 1981-1982 and 1982-1983, mean population $\bar{a}$ values for number of lost fruits and standing crop size are statistically indistinguishable $(P>.95)$, while they differ significantly in 1983-1984 $(F=5.01$, df $=2,44$, $P=.011)$, and marginally in 1980-1981 $(F=3.30$, $\mathrm{df}=1,39, P=.08)$. In these two seasons, mean $\bar{a}$ for lost fruits (July and January, respectively) lagged behind the corresponding value for standing crops (April and October) by $\approx 3$ mo.

Seasonal patterns: proportions. - The proportions of spoiled and fallen fruits relative to the total number of fruits present changed seasonally (Fig. 7). Fallen fruits were less abundant than spoiled fruits. They tended to be most abundant in autumn-winter, and least abundant in spring-summer, but there was strong annual variation. The proportion of spoiled fruits fluctuated seasonally and among years (Fig. 7). Peaks could occur any time of year. June and September peaks were the most predictable, occurring in three out of four years. In general, these data indicate that fruit losses at the population level varied unpredictably. Although the 
seasonal distribution of (relative) fruit losses changed among years, average annual fruit loss did not change significantly $(H=1.83, \mathrm{df}=3, P=.61$, for spoiled fruits; $H=1.24$, df $=3, P=.74$, for fallen fruits; Kruskal-Wallis tests on monthly averages for individual plants).

Relation to fruit size. - During the period November 1980-May 1981, the size of fruits spoiled on, and fallen beneath, study plants was recorded, in addition to that of intact fruits on the same individuals. Only fruits without apparent signs of desiccation (which would reduce size) were measured. Although the data refer to a relatively short period, they reveal significant size heterogeneity among the three groups $(F=18.50, \mathrm{df}=$ $2,2443, P<.0001)$. Average diameter increases from intact (7.11 $\pm 0.72 \mathrm{~mm}, N=2282)$ through fallen $(7.33 \pm 0.69 \mathrm{~mm}, N=122)$ to spoiled $(7.70 \pm 0.76$ $\mathrm{mm}, N=42)$ fruits. The three possible pairwise comparisons between groups yield significant results $(P<$ .01 , Student-Newman-Keuls test). As both fruit size and probability of damage varied seasonally, differential size of intact and damaged fruits could simply be an indirect consequence of largest fruits being predominantly produced at times of highest, and smallest fruits at times of lowest, damage probability. A twoway analysis of variance was performed on fruit diameter using fruit condition [intact vs. (fallen + spoiled)] and month as categorizing factors. Fallen and spoiled fruits were combined to obtain adequate cell sample sizes. Both the condition $(F=11.81, P=.0006)$ and month $(F=9.20, P<.0001)$ effects are significant, while the interaction effect is not. Observed differences in size of intact and lost fruits thus persisted after accounting for temporal variations in fruit diameter, and the nature of this difference did not change seasonally. The average lost fruit was larger than the average intact fruit in all months (November, 7.55 vs. $7.03 \mathrm{~mm}$; December, 7.82 vs. $7.28 \mathrm{~mm}$; January, 7.17 vs $6.95 \mathrm{~mm}$; February, 7.09 vs. $6.87 \mathrm{~mm}$; March, 6.90 vs. $6.77 \mathrm{~mm}$; May, 7.98 vs. $7.68 \mathrm{~mm}$ ).

Relation with standing crop size. - The relation between proportion of spoiled fruits $(P S$, in \%) and size of standing crop $(S C)$ was examined using regression methods ( $P S$ as dependent variable). Actual count data, rather than monthly averages, were considered, excluding data points with $S C$ or $P S=0$ (to avoid increasing correlation coefficients artificially). Linear, exponential, and power functions were fitted to the data for all plants, months, and years combined $(N=783$ data points, each consisting of $P S$ and $S C$ for a single plant on a particular count date). The three functions vary greatly in the proportion of $P S$ variation accounted for. The best fit is provided by the negative power function $P S=83.435 S C^{-0.5607}\left(r^{2}=0.5358\right)$. Exponential $\left(r^{2}=0.2255\right)$ and linear $\left(r^{2}=0.1392\right)$ fits, although statistically significant, explain much smaller fractions of $P S$ variation. The likelihood of damage to a ripe fruit is thus inversely related to crop size, and

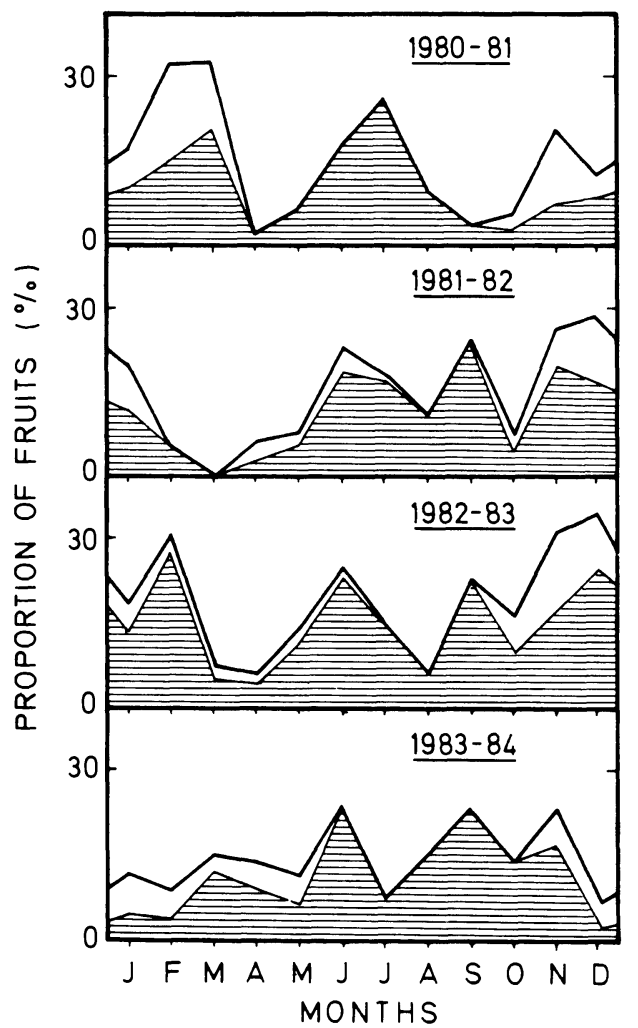

F1G. 7. Variation in the proportional significance of lost fruits with respect to the total of fruits present (=lost + intact). Figures were obtained by averaging values for individual plants. The shaded area under each curve corresponds to spoiled, the open area to fallen fruits (see Fig. 6 legend for definitions of fruit categories). Although a calendar year is used here for reference, annual cycles actually considered (April-March) included portions of two consecutive calendar years.

there is a disproportionate decline in the probability of damage to individual fruits with increasing standing crop size. This decline is particularly steep over the $S C$ range most commonly occurring: increasing $S C$ from 2 to 15 fruits decreases predicted $P S$ from 59 to $21 \%$ (i.e., a fruit in a 15 -fruit crop is expected to be spoiled one-third as frequently as one in a 2 -fruit crop).

The shape of the relation between $P S$ and $S C$ depends on time of year. An overall comparison of separate monthly linear regressions of $\log P S$ against log $S C$ (to linearize power functions) demonstrates highly significant heterogeneity $(F=203, \mathrm{df}=22,759, P<$ $\left.10^{-9}\right)$, resulting from differences in both elevation $\left(F=20.1, \mathrm{df}=11,770, P<10^{-9}\right)$ and slope $(F=301$, $\left.\mathrm{df}=11,759, P<10^{-9}\right)$. Regression coefficients are negative and statistically significant in all months, ranging from -0.227 to $-0.831(\bar{X} \pm \mathrm{SD}=-0.502 \pm$ $0.154, N=12$ ). Although there is not a well-defined seasonal cycle in the magnitude of regression coefficients, lower absolute values tend to occur in MayJuly, and higher absolute values in September-January. The disproportionate reduction in the rate of fruit spoilage resulting from increased crop size was thus 


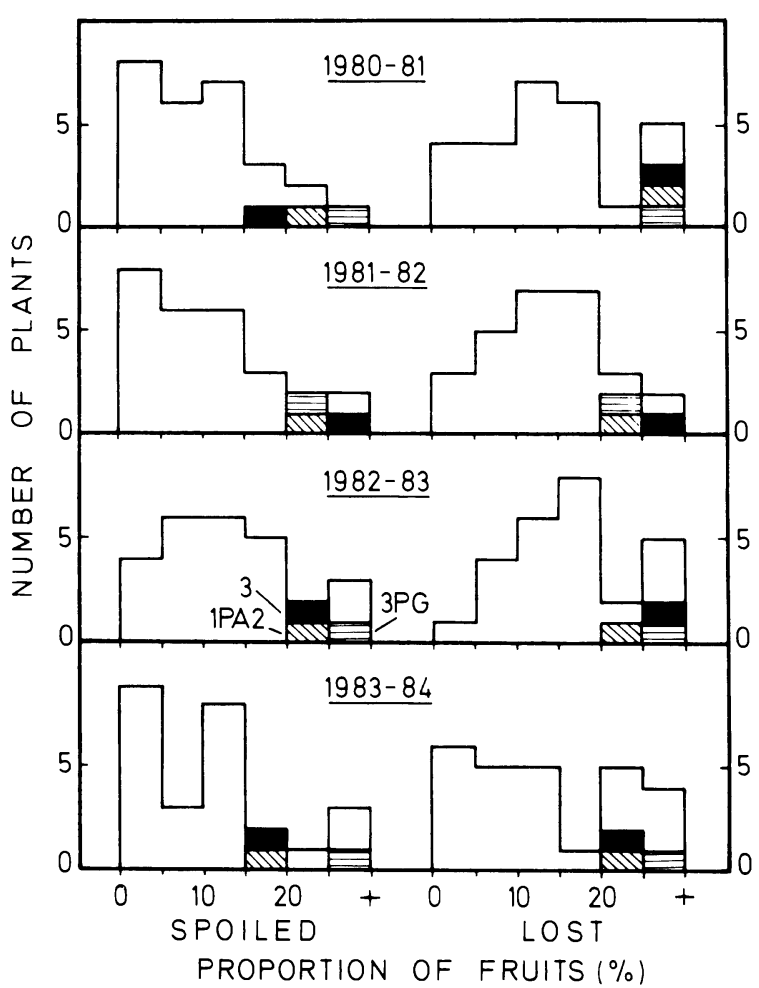

FIG. 8. Frequency distributions of average proportions of spoiled and lost fruits in the four study seasons. Filled or shaded boxes indicate the position of three selected plants in different years.

less pronounced in the former period, more so in the latter.

Comparison of separate regressions for individual plants also reveals overall significant heterogeneity $(F=$ 119 , df $\left.=54,729, P<10^{-9}\right)$, due to individual differences in slope $\left(F=4.15, \mathrm{df}=26,729, P<10^{-9}\right)$ and elevation $\left(F=211\right.$, df $\left.=26,755, P<10^{-9}\right)$. Regression coefficients are negative and significant for all plants, ranging from -0.204 to $-0.980(\bar{X} \pm \mathrm{SD}=-0.631 \pm$ $0.226, N=27)$. The decrease in $P S$ with increasing $S C$ thus takes place at broadly different rates in different individuals.

Individual and annual variation. - Annual averages for the proportions of spoiled and lost fruits were obtained for each plant (Fig. 8). Medians of distributions fall around $10 \%$ (spoiled) and 15\% (lost) of total fruits present. There is no significant interannual heterogeneity in any of these magnitudes $(H=2.51$, df $=3$, $P=.47 ; H=2.42$, df $=3, P=.49 ;$ Kruskal-Wallis test, spoiled and lost fruits, respectively). Broad variation among individuals in average proportions of spoiled and lost fruits was present in the population in all years (Fig. 8). Differences between individuals tend to remain consistent from year to year. Out of six possible between-year pairwise contrasts, there are five $(\%$ spoiled) and three ( $\%$ lost $)$ significant $(P<.05$ or better $)$ positive rank correlations between the respective percentages for the same plant in different years.

\section{Variability and seed output}

It has been shown so far that broad individual variation in a diverse array of attributes was present in the $O$. quadripartita population studied. These included fruiting phenology, crop size, fruit dimensions and proportions, and various parameters related to fruit damage rates. This section examines the degree to which variation in these features translated into differential relative contributions to the total reproductive output of the population (in terms of total seed numbers dispersed).

An estimate of the proportion of seeds contributed by each plant to the total of seeds dispersed (\%SEED) was computed by summing monthly averages of intact fruits for each plant, and then dividing this figure by the total sum for the population. This magnitude (averaged over the 4-yr period), which is roughly proportional to a plant-specific weighting factor for realized reproductive output, has been used as a dependent variable. Independent variables considered are (4-yr data combined or averaged): (1) total fruit number (TFN), the sum of monthly averages for intact plus lost fruits; (2) rate of dispersal success (RDS), sum of intact fruits/TFN; (3) center of fruiting period (CFP), as defined earlier; (4) average mass of pulp per fruit (PULP); (5) fruit diameter (DIAM); (6) slope of the regression relating log percent spoiled fruit and log standing crop (SLOP); (7) mean standing crop size (ASC); (8) diameter of shrub's vertical projection (AD); (9) number of open flowers averaged over the flowering period (NFL); (10) length of the flowering period (LFL).

On the basis of biological considerations and preliminary analyses of patterns of partial correlations, these variables have been linked into a hierarchical "causality" diagram (Fig. 9). The strength of causality was then estimated for each elemental relation by running multiple stepwise regressions having as respective dependent variables those at the nodes of the diagram, and as independent ones those at the origin of arrows converging at the node. Results provided estimates of the proportion of variation accounted for (increase in $R^{2}$ ) by each influential variable, holding the others constant. It must be noted that this method does not produce a "path diagram" in a strict sense (see, e.g., Sokal and Rohlf 1981), as variance proportions refer exclusively to the variable at the extreme of the arrow concerned. Analyses performed on the original and transformed data (proportions with arcsine, masses and TFN with logarithm) yielded identical results, and those for untransformed data are presented here. Similarly, correcting \%SEED by average seed mass (multiplying by mean seed mass/seed mass of the smallest seeded individual) did not affect results.

Total fruit number (TFN) explains $96.9 \%$ of $\%$ SEED variation, while rate of dispersal (RDS) accounts for a further $0.2 \%$. Only $2.9 \%$ of $\%$ SEED variation remains unexplained by these two variables. Of the three de- 
pendent variables used in the regression for TFN, number of flowers (NFL) accounts for $48.6 \%$, length of flowering (LFL) for $1.1 \%$, and plant size (AD) for $1.0 \%$, of TFN variation, while $49.3 \%$ remains unexplained. Finally, in the regression for dispersal rate (RDS), pulp mass (PULP) accounts for $2.4 \%$, fruit diameter (DIAM) for $6.8 \%$, regression slope (SLOP) for $8.8 \%$, and average standing crop for $11.3 \%$. Unexplained RDS variation amounts to $70.8 \%$. As CFP values may not be reduced to a linear scale, this variable was excluded from regression analyses, and its significance evaluated by one-way analyses of variance (CFP as categorizing factor). Results were not significant for either $\operatorname{RDS}(F=$ $0.28, \mathrm{df}=3,22, P=.84)$ or $\%$ SEED $(F=0.98, \mathrm{df}=$ $3,22, P=.42$ ), indicating that fruiting phenology has no influence on these variables.

Interannual consistency of the major patterns revealed by the above analysis was examined by running separate stepwise regressions of \%SEED against TFN and RDS for each year. Proportions of \%SEED variation explained by TFN $(99.2,98.4,98.7$, and 96.2\%, 1980-1981 through 1983-1984, respectively) and RDS $(0.5,0.8,0.4,0.7 \%)$ remain unchanged from year to year. On the other hand, there are significant rank correlations between the \%SEED's of individual plants in different years for all possible pairwise comparisons $\left(r_{s}=0.580-0.880, N=27, P<.002\right.$ or better $)$.

\section{DISCUSSION}

\section{Individual variability}

The preceding analyses have shown broad individual variation in fruiting schedule, crop size, and fruit characteristics of $O$. quadripartita plants. Extreme phenotypical variation is a conspicuous feature of annual root hemiparasites. Although most available evidence refers to morphological traits (Hambler 1958, Smith 1963 , Yeo 1964, Bobear 1969, Karlsson 1974), broad variability has also been reported for reproductive attributes (Salisbury 1942, Atsatt 1970a, b, Atsatt and Guldberg 1978). Studies on woody root hemiparasites are comparatively scarce, but these also reveal considerable intraspecific variability (Sedgley 1982 and the present study). Increased genetic diversity of hemiparasites relative to other plants seems effectively to account for increased phenotypical variation (Atsatt 1970 a, $b$, Atsatt and Strong 1970, Atsatt and Guldberg 1978).

Phenology, crop size, and fruit characteristics of $O$. quadripartita differed in the degree to which individual differences remained consistent from year to year. Annual variation in crop size was similar in all individuals, and is attributable to variation in summer rainfall, through its influence on latent ovary abortion rates. Although summer drought is characteristic of Mediterranean climates, small rains may have a disproportionate importance for many species that, like $O$. quadripartita, enlarge or ripen fleshy fruits during the

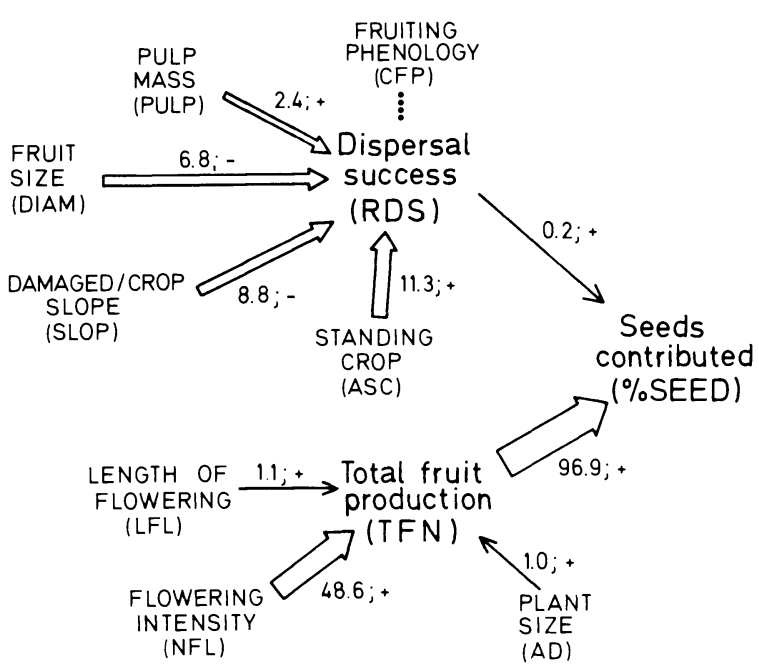

FIG. 9. Predictive value of dispersal success (RDS) and total fruit production (TFN) in explaining individual differences in relative contribution to total seeds dispersed by the 27 -plant study population (\%SEED), 4-yr average data. Shown are also the effects of relevant variables on RDS and TFN. Parameters at the tip of arrows were used as dependent, and those at the base as independent, variables in multiple regression analyses. Figures beside arrows denote the percent variance (increase in $R^{2}$ ) accounted for by the independent variable, and the sign of the regression coefficient (width of arrows approximately depicts $R^{2}$ increase).

summer (see also Sala and Lauenroth 1982). Annual variation in phenology and fruit characteristics did not affect all individuals similarly. Observed annual changes at the population level were presumably the consequence of some environmental change (e.g., crop reduction and phenological shift in 1983-1984 dependent on an unusually long dry season; see Herrera $1984 b$ : Fig. 2), and individuals seemed to respond differently to these changes. Crop size seems therefore a less plastic character than either phenology or fruit features. Individual differences in crop size were related to flower number (see also Herrera $1985 b$ ), which did not change among years. As plant size (height, basal diameter) was unrelated to either crop size or flower number (NFL, as defined earlier), this observation points to the existence of intrinsic individual differences in flower production. These reproductive differences may stem from genetic differences, host species, or most likely a combination of these (Atsatt 1970a, Atsatt and Strong 1970).

Fruit characteristics seemed to be a particularly plastic feature in $O$. quadripartita. Individuals differed greatly in average fruit size, seed mass, pulp mass per fruit, and proportion of pulp and seed biomass in individual drupes. Plants may produce either pulp- or seed-dominated fruits. Furthermore, superimposed on this general pattern of individual variation are significant within-plant seasonal changes, and interplant and interannual differences in the way fruit characteristics change seasonally. The final outcome is a highly unpredictable, temporally inconsistent pattern of indi- 
vidual variability in fruit features. Fruit diameter tends to be the least variable and pulp mass the most variable characteristic. Sedgley (1982), discussing the high variability of the fruits of Santalum acuminatum (Santalaceae), a root hemiparasitic treelet from Australia, reported coefficients of variation between trees for fruit diameter (10.1\%), pulp mass (28.3\%), and seed mass $(27.2 \%)$ strikingly similar to those found here for $O$. quadripartita.

\section{Dispersal consequences of variable traits}

At all times of the year, damaged fruits are significantly larger than intact ones; this is consistent with a lower dispersal probability for larger fruits. This effect may be attributed to decreased handling efficiency by birds as fruit size increases (Wheelwright 1985a). Judging from the mouth width of the most common local frugivores, the dimensions of $O$. quadripartita fruits fall near the upper limit of fruit size that they can swallow (see also Herrera 1984a). On the other hand, as increased fruit diameter is mainly a consequence of increased pulp mass, greater probability of damage incurred by large fruits may also be related to increased attractiveness to pulp-feeding invertebrates. Most of these are infrequent fliers, or do not fly at all, and the few ripe fruits instantaneously available on a bush represent a patchy food resource that would be most efficiently exploited by selecting the individually most rewarding items.

The proportion of damaged fruits in a bush is related to standing crop size by a negative power function, with the decline in damage being particularly steep over the standing crop size range occurring most commonly. The relation holds for individual plants considered separately, and also for monthly data sets even though there is significant interplant and monthly variation in the rate of damage reduction with increasing standing crop. For a plant, likelihood of losing an individual fruit is negatively related to the number of ripe fruits instantaneously present.

Field studies in tropical and temperate habitats have often revealed positive linear or very weakly curvilinear relations between dispersal rates and crop size (Howe and Vande Kerckhove 1979, Howe 1980, McDonnell et al. 1984, Courtney and Manzur 1985). No study had previously reported a monotonically, exponentially increasing relation of dispersal rate and standing crop similar to that found here for $O$. quadripartita. Of all plants studied to date, $O$. quadripartita is the one for which increasing crop size produces the most disproportionate improvement in dispersal rate over as narrow a range of standing crop size.

The probability of damage to ripe fruits change between seasons, but there is no consistent pattern (between years) as to time of damage. The only discernible trends are a distinct increase in damage in summer, and a greater abundance of fallen fruits in autumnwinter. During the summer, lost fruits are almost en- tirely made up of spoiled fruits, which reflects the greater abundance and activity of insect frugivores (C. M. Herrera, personal observation). As fallen fruits are largely the consequence of foraging birds, their greater abundance in autumn-winter is consistent with greater numbers of avian frugivores (compare Figs. 5 and 7). In terms of absolute numbers, fruit loss is not consistently related to the temporal variation in standing crop size. Seasonal variation of fruit losses was synchronous with that of intact fruits in two years, and lagged behind it by $\approx 3 \mathrm{mo}$ in the other two. In conclusion, there is not a distinct seasonal pattern of fruit damage and it seems to change erratically between years. Accordingly, there is no apparent relation between a plant's fruiting phenology and the probability of dispersal of its seeds, except that summer-fruiting predictably results in greater relative (predispersal) seed losses. Although it has not been considered here, phenology-related variation in postdispersal seed success (survival and germination probabilities) might be important. Seasonal changes in seed predation risks could affect survival prospects of seeds dispersed at different times. Furthermore, coincidence of dispersal time with the autumn-winter rainy season might seem advantageous for germination, but $O$. quadripartita seeds have a dormancy period lasting for $1 \mathrm{yr}$ at least (C. M. Herrera, personal observation).

Summarizing, of the three factors considered, variability in crop and fruit size, did produce variation in dispersal success, while variability in fruiting phenology did not. A trade-off seems to exist between fruit size and number, since these variables tend to vary inversely across plants $(r=-0.409, N=27, P=.038)$. On the gradient thus defined, plants producing large crops of small fruits are expected to have the greatest, and those with small crops of large fruits the least, dispersal success.

\section{Correlates of realized reproductive output}

The method used here to estimate realized seed output yields a comparative index of the proportional contribution of female individuals to the total seeds dispersed by the study population (\%SEED). This index should be considered as roughly proportional to fitness if seeds from all individuals are similar in their probability of producing a successful seedling. Broad individual variability in seed size suggests that this is unlikely in $O$. quadripartita. In general, seed size is a good predictor of the likelihood of seedling establishment success through effects upon germination and seedling vigor (e.g., Kaufmann and McFadden 1960, Symonides 1978, Weis 1982, Dunlap and Barnett 1983). Seed size may be particularly important in $O$. quadripartita, whose seedlings have to survive on their own reserves until haustorial connections are established with a host (up to $1 \mathrm{yr}$; C. M. Herrera, personal $o b$ servation). To account for these effects, \%SEED values were corrected for differential seed mass, but this pro- 
duced no modification of results. Accordingly, if seed mass actually accounts for a substantial fraction of variation in the probability of a seed eventually producing a successful seedling, valid inferences can be drawn using \%SEED figures as fitness predictors.

Variation in dispersal success and total fruit production, the two factors most directly affecting \%SEED, is not readily explained by the "conventional" variables examined here. Regression analyses for dispersal success (RDS) show the influence, discussed above, of mean standing crop, slope of the \% spoiled vs. standing crop regression, fruit size, and pulp mass (in decreasing order of importance). These variables account for only $29.2 \%$ of individual variation in RDS. Flower number, length of flowering, and plant size account for $50.7 \%$ of variation in total fruit production (TFN). Unknown sources account for as much as 70.8 and $49.3 \%$ of RDS and TFN variation, respectively, thus demonstrating that the variables considered are fairly poor predictors of dispersal rate. Unexplained variation should be attributed to random effects or variables not accounted for here (e.g., spatial location relative to simultaneously fruiting plants, Herrera 1984c).

Variation in \%SEED is almost fully explained by variation in total fruit production (TFN, 96.9\%), while the role of dispersal success is negligible (RDS, $0.2 \%$ ). This pattern is strongly consistent from year to year. Accordingly, components of interindividual variation that actually are influential on the probability of dispersal of fruits (RDS) are eventually unimportant in accounting for individual variation in relative contribution to the population's seed output. The overwhelming importance of individual variation in fruit production virtually cancels any influence of rather weak differences in dispersal success; an equivalent statement is that variance in absolute numbers offsets variance in rates. In conclusion, dispersal-related traits, although relevant to dispersal rates, are irrelevant to individual differences in fitness (because dispersal rates are irrelevant to fitness).

In $O$. quadripartita, a substantial amount of observed variation in fecundity remains unexplained by the variables considered (including plant size). This may be attributed, at least in part, to its condition of hemiparasite favoring phenotypical canalization by the host (Atsatt 1970b). Furthermore, age differences may obscure patterns of inherent individual variability in fecundity in perennial species (Piñero and Sarukhán 1982) because differences in fecundity resulting from "size hierarchies" (Weiner and Solbrig 1984) may depend on environmental factors rather than genetic differences (Solbrig 1981, Dolan 1984, Dolan and Sharitz 1984). Experiments by Hatgerink and Bazzaz (1984) demonstrate that stochastic events during germination and early establishment actually may override genetic determinants of fitness. The lack of predictable selection against certain genotypes should contribute to the maintenance of genetic diversity and, more impor- tantly, may explain why broad variation in fecundity is so widespread in plant populations in spite of the obvious penalty to the less fecund individuals.

\section{CONCLUSION}

Although individual variation in dispersal-related traits actually results in differential dispersal success of $O$. quadripartita plants, these differences are not expected to translate into individual differences in fitness.

The main factor responsible for this conclusion is that individual variability in fecundity far exceeds variability in dispersal rate. (The extreme phenotypical variation exhibited by $O$. quadripartita produces only moderate variability in dispersal rates.) Extreme differences in fecundity, such as those found in $O$. quadripartita (most often associated with skewed distributions), have been reported for numerous annual and perennial plants in the tropics and elsewhere (e.g., Schaal 1980, Bullock and Bawa 1981, Bullock 1982, Piñero and Sarukhán 1982, Bullock et al. 1983, Schmitt 1983, Wolfe 1983), and the phenomenon thus seems to be widespread. If the magnitude of individual variation in dispersal rate is as small as it seems to be (Howe and De Steven 1979, Howe 1980, 1983, Howe and Vande Kerckhove 1981), it may not compensate for the large differences in fecundity ordinarily found. The possibility exists, therefore, that previous studies on the ecology of seed dispersal relying on assessment of differential rates rather than differential absolute seed outputs may have been doing little more than analyzing what (under present-day conditions) is just environmental noise from the evolutionary perspective of the plants. For $O$. quadripartita, at least, patterns of variation described in detail in this paper appear to be largely noise in the context of potential disperser-mediated evolutionary change. (It must be noted that this "rates-versus-number" problem is not exclusive to seed dispersal research, but may also affect seed predation and pollination studies [De Steven 1983, Schmitt 1983, Zimmerman and Gross 1984].)

Many wood species of the Mediterranean flora have not evolved under current ecological conditions, but rather have been selected out of a diverse array of species that evolved in Tertiary environments under a warm, summer-rain, tropical climate (Raven 1971, 1973, Axelrod 1975). O. quadripartita belongs in this category, and its unusual phenology may be attributed to its tropical relict condition, apparently having changed little since the initiation of Mediterranean conditions in the Pliocene (Herrera 1984b, 1985b,c). Some apparently puzzling dispersal traits of Cneorum tricoccon (Cneoraceae), another very old Mediterranean taxon, have been also attributed to its being a Tertiary relict evolved in a tropical environment (Müller 1933: 402). Furthermore, evidence supporting the constancy, over geological time, of dispersal traits has been presented for other Mediterranean vertebrate-dispersed taxa of Tertiary origin (Laurus, Pistacia) (Her- 
rera 1986). The present study has provided for the first time the elements for an explanation of the persistence over long periods of dispersal traits presumably evolved in ecologically distant scenarios, very different from current ones in the composition of the animal assemblage with which the plant interacts for seed dispersal.

\section{ACKNOWLEDGMENTS}

I thank Carolina Carazo and Manolo Carrión for technical assistance during the preparation of this paper; Dori for her sustained enthusiasm for this project, permanent encouragement, and sharing a part of the field work; and Carlitos for help in arranging plants for Fig. 1.

\section{Literature Cited}

Anonymous. 1962. Estudio agrobiológico de la Provincia de Sevilla. Diputación Provincial, Sevilla, Spain.

Atsatt, P. R. 1970a. The population biology of annual grassland hemiparasites. II. Reproductive patterns in Orthocarpus. Evolution 24:598-612.

$1970 b$. Hemiparasitic flowering plants: phenotypic canalization by hosts. Nature 225:1161-1163.

Atsatt, P. R., and L. D. Guldberg. 1978. Host influence on floral variability in Orthocarpus densiflorus (Scrophulariaceae). Plant Systematics and Evolution 129:167-176.

Atsatt, P. R., and D. E. Strong 1970. The population biology of annual grassland hemiparasites. I. The host environment. Evolution 24:278-291.

Axelrod, D. I. 1975. Evolution and biogeography of Madrean-Tethyan sclerophyll vegetation. Annals of the Missouri Botanical Garden 62:280-334.

Bobear, J. B. 1969. An analysis of populations of Irish Euphrasia. Watsonia 7:68-91.

Bramwell, D., and Z. Bramwell. 1974. Wild flowers of the Canary Islands. Thornes, London, England.

Bullock, S. H. 1982. Population structure and reproduction in the Neotropical dioecious tree Compsoneura sprucei. Oecologia (Berlin) 55:238-242.

Bullock, S. H., and K. S. Bawa. 1981. Sexual dimorphism and the annual flowering pattern in Jacaratia dolichaula (D. Smith) Woodson (Caricaceae) in a Costa Rican rain forest. Ecology 62:1494-1504.

Bullock, S. H., J. H. Beach, and K. S. Bawa. 1983. Episodic flowering and sexual dimorphism in Guarea rhopalocarpa in a Costa Rican rain forest. Ecology 64:851-861.

Courtney, S. P., and M. I. Manzur. 1985. Fruiting and fitness in Crataegus monogyna: the effects of frugivores and seed predators. Oikos 44:398-406.

De Steven, D. 1983. Reproductive consequences of insect seed predation in Hamamelis virginiana. Ecology 64:8998.

Dolan, R. W. 1984. The effect of seed size and maternal source on individual size in a population of Ludwigia leptocarpa (Onagraceae). American Journal of Botany 71:13021307.

Dolan, R. W., and R. R. Sharitz. 1984. Population dynamics of Ludwigia leptocarpa (Onagraceae) and some factors affecting size hierarchies in a natural population. Journal of Ecology 72:1031-1041.

Dunlap, J. R., and J. P. Barnett. 1983. Influence of seed size on germination and early development of loblolly pine ( $\mathrm{Pi}$ nus taeda L.) germinants. Canadian Journal of Forest Research 13:40-44.

Ferrarini, E. 1950. Il parassitismo di Osyris alba L. Nuovo Giornale Botanico Italiano, New Series 57:351-381.

Hambler, D. J. 1958. Some taxonomic investigations on the genus Rhinanthus. Watsonia 4:101-116.
Hartgerink, A. P., and F. A. Bazzaz. 1984. Seedling-scale environmental heterogeneity influences individual fitness and population structure. Ecology 65:198-206.

Herrera, C. M. 1981. Fruit variation and competition for dispersers in natural populations of Smilax aspera. Oikos 36:51-58.

- 1982. Seasonal variation in the quality of fruits and diffuse coevolution between plants and avian dispersers. Ecology 63:773-785.

— 1984a. A study of avian frugivores, bird-dispersed plants, and their interaction in Mediterranean scrublands. Ecological Monographs 54:1-23.

1984b. The annual cycle of Osyris quadripartita, a hemiparasitic dioecious shrub of Mediterranean scrublands. Journal of Ecology 72:1065-1078.

1984c. Seed dispersal and fitness determinants in wild rose: combined effects of hawthorn, birds, mice, and browsing ungulates. Oecologia (Berlin) 63:386-393.

1985 a. Determinants of plant-animal coevolution: the case of mutualistic dispersal of seeds by vertebrates. Oikos 44:132-141.

- 1985b. Predispersal reproductive biology of female Osyris quadripartita (Santalaceae), a hemiparasitic dioecious shrub of Mediterranean scrublands. Botanical Journal of the Linnean Society 90:113-127.

- $1985 c$. Tipos morfológicos y funcionales en plantas del matorral mediterráneo del sur de España. Studia Oecologica 3:7-33.

-1986. Vertebrate-dispersed plants: why they don't behave the way they should. Pages 5-18 in A. Estrada and T. H. Fleming, editors. Frugivores and seed dispersal. Junk, The Hague, The Netherlands.

- 1987. Vertebrate-dispersed plants of the Iberian Peninsula: a study of fruit characteristics. Ecological Monographs 57:305-331.

Herrera, J. 1985. Biología reproductiva del matorral de Doñana. Dissertation. University of Sevilla, Sevilla, Spain.

Howe, H. F. 1977. Bird activity and seed dispersal of a tropical wet forest tree. Ecology 58:539-550.

-1980. Monkey dispersal and waste of a Neotropical fruit. Ecology 61:944-959.

- 1983. Annual variation in a Neotropical seed-dispersal system. Pages 211-227 in S. L. Sutton, T. Whitmore, and A. C. Chadwick, editors. The tropical rain forest: ecology and management. Blackwell, Oxford, England.

- 1984. Constraints on the evolution of mutualism. American Naturalist 123:764-777.

Howe, H. F., and D. De Steven. 1979. Fruit production, migrant bird visitation, and seed dispersal of Guarea glabra in Panama. Oecologia (Berlin) 39:185-196.

Howe, H. F., and G. F. Estabrook. 1977. On intraspecific competition for avian dispersers in tropical trees. American Naturalist 111:817-832.

Howe, H. F., and G. A. Vande Kerckhove. 1979. Fecundity and seed dispersal of a tropical tree. Ecology 60:180-189.

Howe, H. F., and G. A. Vande Kerckhove. 1980. Nutmeg dispersal by tropical birds. Science 210:925-927.

Howe, H. F., and G. A. Vande Kerckhove. 1981. Removal of wild nutmeg (Virola surinamensis) crops by birds. Ecology 62:1093-1106.

Jahandiez, E., and R. Maire. 1932. Catalogue des plantes du Maroc. Volume 2. Imprimerie Minerva, Algiers, Algeria.

Jalas, J., and J. Suominen. 1976. Atlas florae Europaeae. Distribution of vascular plants in Europe. Volume 3. Salicaceae to Balanophoraceae. Societas Biologica Fennica Vanamo, Helsinki, Finland.

Janzen, D. H., and P. S. Martin 1982. Neotropical anachronisms: the fruits the Gomphotheres ate. Science 215:1927. 
Karlsson, T. 1974. Recurrent ecotypic variation in Rhinantheae and Gentianaceae in relation to hemiparasitism and mycotrophy. Botaniska Notiser 127:527-539.

Kaufmann, M. L., and A. D. McFadden. 1960. The competitive interaction between barley plants grown from large and small seeds. Canadian Journal of Plant Science 40:623629.

Kuijt, J. 1969. The biology of parasitic flowering plants. University of California Press, Berkeley, California, USA.

McDonnell, M. J., E. W. Stiles, G. P. Cheplick, and J. J. Armesto. 1984. Bird-dispersal of Phytolacca americana L. and the influence of fruit removal on subsequent fruit development. American Journal of Botany 71:895-901.

McKey, D. 1975. The ecology of coevolved seed dispersal systems. Pages 159-191 in L. E. Gilbert and P. H. Raven, editors. Coevolution of animals and plants. University of Texas Press, Austin, Texas, USA.

Ministerio de Agricultura. 1975. Mapa de cultivos y aprovechamientos. Carmona (Sevilla). Servicio de Publicaciones Agrarias, Madrid, Spain.

Montero, J. L., and J. L. González. 1974. Diagramas bioclimáticos. Ministerio de Agricultura, Madrid, Spain.

Müller, P. 1933. Verbreitungsbiologie der Garigueflora. Beihefte Botanisches Centralblatt 50:395-469.

Piñero, D., and J. Sarukhán. 1982. Reproductive behaviour and its individual variability in a tropical palm, Astrocaryum mexicanum. Journal of Ecology 70:461-472.

Quézel, P., and S. Santa. 1962. Nouvelle flore de l'Algerie et des régions désertiques méridionales. Volume 1. Centre National de la Recherche Scientifique, Paris, France.

Raven, P. H. 1971. The relationships between 'Mediterranean' floras. Pages 119-134 in P. H. Davis, P. C. Harper, and I. C. Hedge, editors. Plant life of South-west Asia. Botanical Society of Edinburgh, Edinburgh, United Kingdom.

1973. Plant biogeography. Introduction. Pages 211212 in F. di Castri and H. A. Mooney, editors. Mediterranean-type ecosystems. Springer-Verlag, West Berlin, Germany.

Sala, O. E., and W. K. Lauenroth. 1982. Small rainfall events: an ecological role in semiarid regions. Oecologia (Berlin) 53:301-304.

Salisbury, E. J. 1942. The reproductive capacity of plants. Bell, London, England.

Schaal, B. A. 1980. Reproductive capacity and seed size in Lupinus texensis. American Journal of Botany 67:703-709.

Schmitt, J. 1983. Individual flowering phenology, plant size, and reproductive success in Linanthus androsaceus, a California annual. Oecologia (Berlin) 59:135-140.

Sedgley, M. 1982. Preliminary assessment of an orchard of quandong seedling trees. Journal of the Australian Institute of Agricultural Science 48:52-56.

Smith, A. J. E. 1963. Variation in Melampyrum pratense L. Watsonia 5: 336-367.

Snow, D. W. 1965. A possible selective factor in the evolution of fruiting seasons in tropical forest. Oikos 15:274281 .

1971. Evolutionary aspects of fruit-eating by birds. Ibis 113:194-202.

Sokal, R. R., and F. J. Rohlf. 1981. Biometry. Second edition. Freeman, San Francisco, California, USA.

Solbrig, O. T. 1981. Studies on the population biology of the genus Viola. II. The effect of plant size on fitness in Viola sororia. Evolution 35:1080-1093.

Stiles, E. 1980. Patterns of fruit presentation and seed dispersal in bird-disseminated woody plants in the eastern deciduous forest. American Naturalist 116:670-688.

Symonides, E. 1978. Effect of seed size, density and depth of sowing on the germination and survival of psammophyte seedlings. Ekologia Polska 26:123-139.

Weiner, J., and O. T. Solbrig. 1984. The meaning and measurement of size hierarchies in plant populations. Oecologia (Berlin) 61:334-336.

Weis, I. M. 1982. The effects of propagule size on germination and seedling growth in Mirabilis hirsuta. Canadian Journal of Botany 60:1868-1874

Wheelwright, N. T. 1985a. Fruit size, gape width, and the diets of fruit-eating birds. Ecology 66:808-818.

. $1985 b$. Competition for dispersers, and the timing of flowering and fruiting in a guild of tropical trees. Oikos 44:465-477.

Wheelwright, N. T., and G. H. Orians. 1982. Seed dispersal by animals: contrasts with pollen dispersal, problems of terminology, and constraints on coevolution. American Naturalist 119:402-413.

Wolfe, L. M. 1983. The effect of plant size on reproductive characteristics in Erythronium americanum (Liliaceae). Canadian Journal of Botany 61:3489-3493.

Yeo, P. F. 1964. The growth of Euphrasia in cultivation. Watsonia 6:1-24.

Zar, J. H. 1984. Biostatistical analysis. Second edition. Prentice-Hall, Englewood Cliffs, New Jersey, USA.

Zimmerman, M. 1984. Reproduction in Polemonium: a five year study of seed production and implications for competition for pollinator service. Oikos 42:225-228.

Zimmerman, M., and R. S. Gross. 1984. The relationship between flowering phenology and seed set in an herbaceous perennial plant, Polemonium foliosissimum Gray. American Midland Naturalist 111:185-191. 